\title{
Perspective
}

PERSPECTIVE Actualité en histoire de l'art

Comptes rendus | 2008

Quitterie Cazes, Daniel Cazes, Saint-Sernin de Toulouse : de Saturnin au chef-d'œuvre de l'art roman, Graulhet, Odyssée, 2008

\section{Thomas Creissen}

\section{(2) OpenEdition}

1 Journals

Édition électronique

URL : http://journals.openedition.org/perspective/2954

DOI : 10.4000/perspective.2954

ISSN : 2269-7721

Éditeur

Institut national d'histoire de l'art

Référence électronique

Thomas Creissen, «Quitterie Cazes, Daniel Cazes, Saint-Sernin de Toulouse : de Saturnin au chef-d'œuvre de l'art roman, Graulhet, Odyssée, 2008 », Perspective [En ligne], Comptes rendus, mis en ligne le 23 janvier 2014, consulté le 01 octobre 2020. URL : http://journals.openedition.org/perspective/2954 ; DOI : https://doi.org/10.4000/perspective.2954

Ce document a été généré automatiquement le 1 octobre 2020. 
Quitterie Cazes, Daniel Cazes, SaintSernin de Toulouse : de Saturnin au chef-d'œuvre de l'art roman, Graulhet, Odyssée, 2008

Thomas Creissen

\section{RÉFÉRENCE}

Quitterie Cazes, Daniel Cazes, Saint-Sernin de Toulouse : de Saturnin au chef-d'œuvre de l'art roman, Graulhet, Odyssée, 2008. 
1 Malgré son titre en apparence réducteur, l'ouvrage de Quitterie et Daniel Cazes consacré à Saint-Sernin de Toulouse outrepasse largement le cadre d'une simple monographie: à travers cet exemple, c'est bien une réflexion plus vaste sur un pan de la création romane qui est ici proposée. Soulignons par ailleurs l'extrême qualité des photographies de Michel Escourbiac. Après quelques considérations historiques sur l'origine du lieu de culte, les auteurs s'arrêtent sur la construction d'un

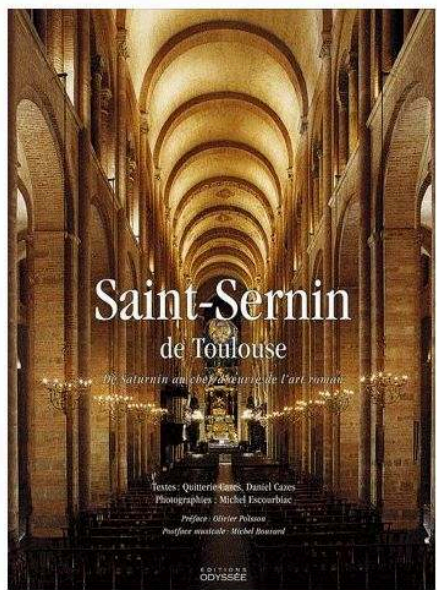
premier monument en l'honneur de Saturnin, très tôt devenu pôle d'inhumation privilégié, ce qui explique la relative profusion de sarcophages sculptés retrouvés sur le site. Les auteurs vont jusqu'à suggérer l'existence d'une production sur le site même de Saint-Sernin. Pour le haut Moyen Âge, les connaissances sont si limitées qu'il reste malheureusement impossible de mesurer un éventuel apport de cette période à la basilique romane. La longue genèse du monument et le contexte historique qui entoure la construction de l'église romane sont clairement présentés à l'aide de dessins hautement didactiques, sans pour autant renouveler radicalement la lecture jusqu'alors retenue. L'étude, exemplaire, amène à distinguer dix étapes principales. Malgré cette chronologie complexe, les auteurs soulignent la remarquable homogénéité de ce monument: l'existence ab initio d'un projet bien défini est manifeste, lequel a pu s'appuyer sur des supports tels que plans ou maquettes. Le plan comme l'élévation de Saint-Sernin sont ensuite rapprochés de ce qui s'est fait ailleurs et avant: il ressort de l'analyse que si cette église est profondément originale dans son résultat, elle n'en est pas moins hautement tributaire de ces antécédents et trouve parfaitement sa place dans une histoire de l'architecture religieuse médiévale. Le reste de l'ouvrage est essentiellement consacré à la sculpture au sein de l'édifice, présentée de manière chronologique. L'ensemble de la production sculptée est ici analysé avec minutie, certaines œuvres étant décrites dans leurs moindres détails avec une rigueur parfois fastidieuse mais néanmoins admirable. 